\title{
PENGENALAN CITRA HURUF HIJAIAH MENGGUNAKAN METODE GRAY LEVEL CO-OCCURRENCE MATRICES (GLCM) DENGAN 4 SUDUT ORIENTASI DAN JARINGAN SYARAF TIRUAN BACKPROPAGATION
}

\author{
(Hijaiiyah Pattern Recognition Using Grey Level Co-Occurrence Matrices (GLCM) \\ Method With 4 Oriented Angle and Backpropagation Artificial Neural Network)
}

\author{
Muhlis Fathurrahman*, Ramaditia Dwiyansaputra \\ Program Studi Teknik Informatika, Fakultas Teknik, Universitas Mataram \\ Jl. Majapahit 62, Mataram, Lombok NTB, INDONESIA \\ Email: muhlisfathurrahman@gmail.com, rama@unram.ac.id
}

\begin{abstract}
Arabic is one of the international languages according to the United Nations (UN) which was adopted by General Council resolution 3190 (XXVIII) as the official language and working language of the General Counsel and Main Committees on 18 December 1973. Arabic can be found in the holy book Al - Qur'an. For a Muslim, it is obligatory to learn and master Arabic in order to read and understand the contents of the Al-Qur'an. job applicants from Indonesia also have to learn Arabic. The Hijaiiyah letter has the same role as the alphabet, which is to compose every word and sentence. Humans have a natural intelligence to be able to recognize each Hijaiiyah letter based on the special characteristics or patterns contained in each letter. However, natural intelligence has deficiencies such as inconsistencies in assessing the similarity of each handwritten Hijaiiyah letter from different people. Therefore, this research will develop a system for identifying or recognizing Hijaiiyah handwritten patterns using the Gray Level Co-occurrence Matrices (GLCM) method with 4 orientation angles and Backpropagation Artificial Neural Network (ANN). Data was collected using the Autodesk Sketchbook application so that can reduce the noise. The purpose of this research is to know the level of accuracy and precision of the classification of the Hijaiiyah letter pattern. In this research, the numbers of data were 1500 images of Hijaiiyah letters. The highest accuracy is $45.1111 \%$ with a precision of $45.1111 \%$.
\end{abstract}

Keywords: Arabic, Hijaiiyah letters, GLCM, Artificial Neural Networks, Backpropagation

*Penulis Korespondensi

\section{Pendahuluan}

Bahasa Arab merupakan salah satu Bahasa internasional menurut Perserikatan Bangsa Bangsa (PBB) yang ditetapkan melalui resolusi Majelis Umum 3190 (XXVIII) sebagai bahasa resmi dan bahasa kerja Majelis Umum dan Komite - Komite Utama pada tanggal 18 Desember 1973 [1]. Bahasa Arab dapat ditemui di dalam kitab suci Al - Qur'an. Bagi seorang muslim wajib untuk mempelajari dan menguasai Bahasa Arab agar dapat membaca dan memahami isi dari Al-Qur'an.

Dalam mempelajari Bahasa Arab harus mengenali setiap huruf tunggal yang disebut dengan huruf hijaiah. Huruf hijaiah memiliki peran yang sama dengan alphabet yaitu untuk menyusun setiap kata dan kalimat. Jika tidak mengenali dan/atau memahami setiap huruf dengan baik, maka sulit untuk berkomunikasi dengan menggunakan sebuah Bahasa tertentu khususnya Bahasa Arab yang memiliki bentuk huruf yang berbeda dengan huruf yang lazim digunakan di Indonesia. Oleh karena itu, mengenali huruf merupakan salah satu faktor utama untuk dapat memahami suatu Bahasa yang baru dipelajari.

Manusia memiliki kecerdasan alami untuk dapat membedakan dan mengenali setiap huruf hijaiah berdasarkan ciri atau pola khusus yang terdapat pada masing - masing hurufnya. Namun kecerdasan alami memiliki kekurangan seperti inkonsistensi dalam menilai tingkat kemiripan dari setiap huruf hijaiah. Salah satu solusi untuk dapat mengenali tulisan tangan huruf hijaiah adalah dengan memanfaatkan pengolahan citra digital. Oleh karena itu penelitian ini akan mengembangkan sistem untuk melakukan identifikasi atau pengenalan pola tulisan tangan huruf hijaiah. 
Pada proses ekstraksi fitur GLCM, parameter ciri yang digunakan yaitu tekstur dari citra huruf hijaiah. Ekstraksi GLCM menghasilkan fitur antara lain energi, kontras, homogenitas, entropi dan korelasi dalam 4 orientasi sudut $\left(0^{\circ}, 45^{\circ}, 90^{\circ}\right.$ dan $\left.135^{\circ}\right)$ [2]. Metode Jaringan Syaraf Tiruan (JST) Backpropagation merupakan metode yang sangat baik dalam menangani masalah pengenalan pola yang kompleks. seperti pengoperasian data, peramalan (prediksi) dan pengenalan pola [3].

Berdasarkan uraian di atas penulis mengajukan sebuah penelitian untuk merancang sebuah model pembelajaran mesin (machine learning) untuk mengklasifikasikan pola huruf hijaiah menggunakan metode GLCM dan JST Backpropagation sebagai media pengenalan huruf Arab (hijaiah). Tingkat akurasi dan presisi dari hasil klasifikasi adalah parameter hasil uji atas metode JST Backpropagation.

\section{TinjauAn PUSTAKa}

Penelitian mengenai pengolahan citra digital (digital image processing) sudah pernah dilakukan oleh beberapa peneliti. Penelitian - penelitian sebelumnya akan dijadikan sebagai rujukan ketika penelitian ini dilaksanakan.

Penelitian - penelitian tersebut antara lain tentang pengenalan pola huruf hijaiah tulisan tangan menggunakan logika fuzzy dengan JST backpropagation memiliki akurasi $69 \%$ dengan menggunakan 420 data set [4], parameter value setiap huruf dan matriks interrelationship, tidak cukup mewakili ciri identik dari setiap huruf dengan baik. Penelitian berikutnya tentang identifikasi tulisan tangan huruf hijaiah dengan metode Euclidian Distance menggunakan 84 data set memiliki akurasi sebesar $84.52 \%$ [5]. Penelitian berikutnya tentang pengenalan tulisan tangan bahasa arab menggunakan metode Probabilistic Neural Network menggunakan 100 data set dengan tingkat akurasi $90.15 \%$, namun sistem hanya dapat mengenali 10 dari 28 huruf hijaiah [6].penelitian lain tentang pengenalan angka arab timur tulisan tangan menggunakan Zone Centroid Zone (ZCZ) dan Backpropagation menggunakan 500 data set memiliki akurasi sebesar $86 \%$ [7]. Penelitian berikutnya tentang identifikasi tulisan Arab dengan menggunakan GLCM dan RNN menggunakan 1219 data set dengan tingkat akurasi $78.75 \%$ [8].

Penelitian terkait lain tentang identifikasi huruf hijaiah berbasis GLCM menggunakan jaringan syaraf tiruan backpropagation menggunakan 600 data set dengan tingkat akurasi $96.11 \%$ [3], penelitian menggunakan 5 fitur yaitu entropi, energi, korelasi, kontras dan homogenitas dengan sudut orientasi $0^{\circ}$. Perpaduan metode ekstraksi fitur GLCM dan metode klasifikasi backpropagation mampu mengenali citra huruf hijaiah dengan sangat baik. Penelitian lain tentang pengenalan tulisan tangan huruf hijaiah sambung menggunakan algoritme template matching correlation menggunakan 84 data set dengan tingkat akurasi sebesar $56.41 \%$ [9]. Penelitian lain tentang implementasi metode $k$-nearest neighbor pada pengenalan pola tekstur citra saliva untuk deteksi ovulasi menggunakan 45 data set dengan tingkat akurasi 93.3\% [10], implementasi pengolahan citra dan klasifikasi k-nearest neighbor untuk membangun aplikasi pembeda daging sapi dan babi menggunakan 60 data set dengan tingkat akurasi 93.33\% [11] dan identifikasi tumbuhan obat herbal berdasarkan citra daun menggunakan algoritme GLCM dan k-nearest neighbor menggunakan 90 data set dengan tingkat akurasi 83.33\% [12], namun ke tiga penelitian terakhir belum teruji untuk data set dengan jumlah yang banyak.

Berdasarkan referensi yang didapatkan oleh penulis tersebut, penggunaan metode ekstraksi fitur GLCM dengan 5 fitur dan 4 susut orientasi mampu menghasilkan akurasi yang tinggi [11], sehingga metode GLCM akan digunakan sebagai metode ekstraksi fitur pada penelitian ini. Metode JST Backpropagation mampu melakukan klasifikasi dengan tingkat akurasi yang tinggi saat dipasangkan dengan metode ekstraksi fitur GLCM. Penelitian ini akan menggunakan metode ekstraksi fitur GLCM dan metode klasifikasi JST Backpropagation dengan preprocessing data menggunakan pola tulisan tangan pada layar smart phone (Autodesk SketchBook) diharapkan dapat melakukan klasifikasi dengan tingkat akurasi dan presisi yang tinggi. Sehingga penulis bermaksud menggunakan metode tersebut untuk melakukan klasifikasi pola huruf hijaiah.

\section{Metode Penelitian}

\subsection{Data}

Pada penelitian ini terdapat beberapa peralatan pendukung yang digunakan antara lain:

a. Matlab R2017a.

b. Microsoft Office 2019.

c. Microsoft Visio 2019.

d. Autodesk Sketchbook.

Data yang digunakan pada penelitian ini adalah citra huruf hijaiah. Pengumpulan data dilakukan dengan cara penulisan oleh responden dengan menggunakan aplikasi Autodesk Sketchbook pada smart phone Android. Pada Autodesk Sketchbook jenis 
pen yang digunakan adalah Inking Pen dengan tinta berwarna hitam, ukuran 12 dan tingkat kegelapan $100 \%$. Data citra yang telah didapatkan dari responden disimpan dalam format ekstensi file (.PNG). Dalam penelitian ini, responden yang dimaksud merupakan pelajar atau mahasiswa yang berusia lebih dari 12 tahun atau minimal telah berada pada jenjang pendidikan SMP sederajat serta cakap dalam menggunakan smart phone Android. Pengambilan data dengan cara tersebut dimaksudkan agar dapat mengurangi noise pada citra huruf hijaiah.

\subsection{Gray Level Co-occurrence Matrices (GLCM)}

Matriks co-occurrence adalah salah satu metode statistik yang dapat digunakan untuk analisis tekstur. Matriks co-occurrence dibentuk dari suatu citra dengan melihat pada piksel - piksel yang berpasangan yang memiliki intensitas tertentu. Penggunaan metode ini berdasar pada hipotesis bahwa dalam suatu tekstur akan terjadi perulangan konfigurasi atau pasangan aras keabuan. Misal, d didefinisikan sebagai jarak antara dua posisi piksel, yaitu $\left(x_{1}, y_{1}\right),\left(x_{2}, y_{2}\right)$ dan $\theta$ didefinisikan sebagai sudut diantara keduanya. Maka matriks co-occurrence didefinisikan sebagai matriks yang menyatakan distribusi spasial antara dua piksel yang bertetangga yang memiliki intensitas $\mathrm{i}$ dan $\mathrm{j}$, yang memiliki jarak d di antara keduanya, dan sudut $\theta$ diantara keduanya. Matriks co-occurrence dinyatakan dengan $P_{i j}$. Suatu piksel yang bertetangga yang memiliki jarak $d$ di antara keduanya, dapat terletak di delapan arah yang berlainan, hal ini ditunjukkan pada Gambar 1 [8].

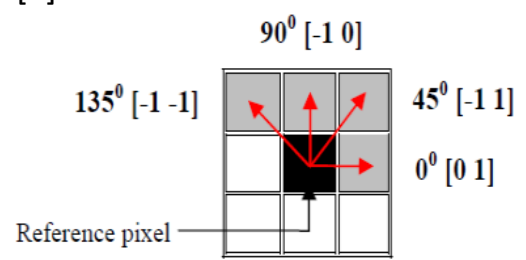

Gambar 1. Piksel bertetangga dalam empat arah [8]

Dalam matriks co-occurrence, terdapat ciri tekstur yang dapat diperoleh dari suatu citra yang digunakan sebagai pembeda antara citra dengan kelas tertentu, dengan kelas lainnya. Ciri - ciri tersebut adalah [13]:

a. Energi (Energy)

$$
f_{1}=\sum_{i} \sum_{j} P_{i j}^{2}
$$

b. Entropi (Entropy)

$$
f_{2}=-\sum_{i} \sum_{j} P_{i j} \log P_{i j}
$$

c. Kontras (Contrast)

$$
f_{3}=\sum_{i} \sum_{j}(i-j)^{2} P_{i j}
$$

d. Homogenitas (Homogeneity)

$$
f_{4}=\sum_{i} \sum_{j} \frac{P_{i, j}}{1+|i-j|}
$$

e. Korelasi (Correlation)

$$
f_{5}=\sum_{i} \sum_{j} \frac{\left(i-\mu_{i}\right)\left(j-\mu_{j}\right)\left(P_{i j}\right)}{\sigma_{i} \sigma_{j}}
$$

$\mu_{i}$ adalah nilai rata - rata elemen kolom ke - i pada matriks $P_{i, j}$

$\mu_{j}$ adalah nilai rata - rata elemen kolom ke - j pada matriks $P_{i, j}$

$\sigma_{i}$ adalah nilai standar deviasi elemen kolom ke $-\mathrm{i}$ pada matriks $P_{i, j}$

$\sigma_{j}$ adalah nilai standar deviasi elemen kolom ke $-\mathrm{j}$ pada matriks $P_{i, j}$

\subsection{Jaringan Syaraf Tiruan (JST) Backpropagation}

JST dengan layer tunggal memiliki keterbatasan dalam pengenalan pola. Kelemahan ini bisa ditanggulangi dengan menambahkan satu atau beberapa layar tersembunyi di antara layer masukan dan layer keluaran. JST backpropagation melatih jaringan mendapatkan keseimbangan antara kemampuan jaringan untuk mengenali pola yang digunakan selama pelatihan serta kemampuan untuk memberikan respons yang benar terhadap pola masukan yang serupa dengan pola yang dipakai selama pelatihan [13].

Backpropagation memiliki beberapa unit (neuron) yang ada dalam satu atau lebih layer tersembunyi. Gambar 3 adalah arsitektur backpropagation multilayer dengan 1 hidden layer. Pada gambar, unit input dilambangkan dengan $\mathrm{X}$, unit hidden dilambangkan dengan $Z$, dan unit output dilambangkan dengan $\mathrm{Y}$. Bobot antara unit input $(\mathrm{X})$ dan unit hidden (Z) dilambangkan dengan $\mathrm{V}$, sedangkan bobot antara unit hidden ( $\mathrm{Z}$ ) dan unit output $(\mathrm{Y})$ dilambangkan dengan $\mathrm{W}$.

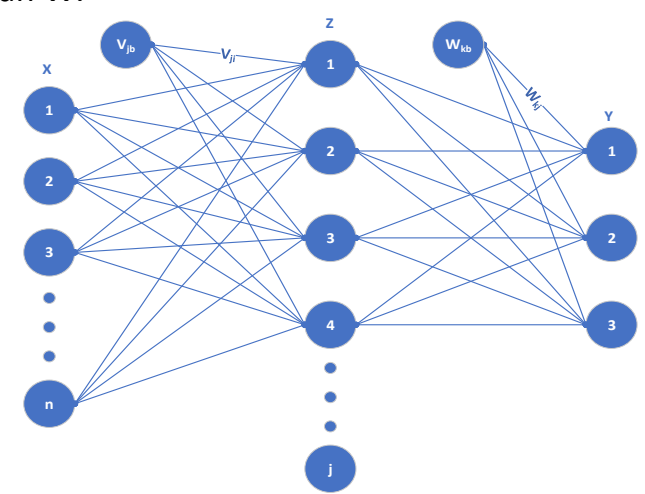

Gambar 2. Model JST backpropagation

Dalam backpropagation, fungsi aktivasi yang dipakai harus memenuhi beberapa syarat yaitu 
kontinu, terdiferensial dengan mudah dan merupakan fungsi yang tidak turun. Salah satu fungsi yang memenuhi ketiga syarat tersebut sehingga sering dipakai adalah fungsi sigmoid biner yang memiliki range $(0,1)[13]$. Persamaan fungsi aktivasi sigmoid biner yaitu sebagai berikut:

$$
\begin{aligned}
& f(x)=\frac{1}{1+e^{-x}} \\
& f^{\prime}(x)=f(x)(1-f(x))
\end{aligned}
$$

Algoritme pelatihan backpropagation terdiri dari proses feedforward dan backpropagation. Algoritme tersebut yaitu sebagai berikut [14]:

Langkah 0: Inisialisasi bobot (ambil bobot awal dengan nilai acak yang cukup kecil).

Langkah 1: Jika kondisi penghentian belum terpenuhi, lakukan langkah 2 sampai 9.

Langkah 2: Untuk setiap pasang data pelatihan, lakukan langkah 3 sampai 8.

Fase I: Step Forward

Langkah 3: Tiap unit masukan $\left(x_{i}, i=1,2, \ldots, n\right)$ menerima sinyal dan meneruskannya ke unit selanjutnya, yaitu lapisan tersembunyi.

Langkah 4: Hitung semua keluaran pada lapisan tersembunyi $\left(Z_{j}, j=1,2, \ldots, p\right)$.

$$
Z_{-} n e t_{j}=v_{0 j}+\sum_{i}^{n} x_{i} v_{i j}
$$

Gunakan fungsi aktifasi untuk menghitung sinyal output-nya:

$$
Z_{j}=f\left(Z_{-} n e t_{j}\right)
$$

Dan kirimkan sinyal tersebut ke semua unit lapisan atasnya (unit - unit output). Langkah ini dilakukan sebanyak jumlah lapisan tersembunyi.

Langkah 5: Hitung semua keluaran jaringan di lapisan output $\left(Y_{k}, k=1,2, \ldots, n\right)$.

$$
Y_{-} n e t_{k}=W_{0 k}+\sum_{j}^{p} Z_{j} W_{j k}
$$

Gunakan fungsi aktifasi untuk menghitung sinyal output-nya:

$$
Y_{k}=f\left(Y_{-} n e t_{k}\right)
$$

Fase II: Backpropagation

Langkah 6: Hitung faktor $\delta$ unit keluaran berdasarkan kesalahan di setiap unit keluaran $\left(Y_{k}, k=1,2, \ldots, n\right)$

$$
\delta_{k}=\left(T_{k}-Y_{k}\right) f^{\prime}\left(Y_{-} n e t_{k}\right)
$$

$\delta$ merupakan unit kesalahan yang akan dipakai dalam perubahan bobot layer di bawahnya (langkah 7).

$f^{\prime}\left(Y_{\_} n e t_{k}\right)$ merupakan fungsi turunan dari fungsi aktifasi sigmoid biner.

Kemudian hitung koreksi bobot (yang nantinya akan digunakan untuk memperbaiki $W_{j k}$ ) dengan laju percepatan $\alpha$

$$
\Delta W_{j k}=\alpha \delta_{k} Z_{j}
$$

Kemudian hitung juga koreksi bias (yang nantinya akan digunakan untuk memperbaiki nilai $W_{0 k}$ )

$$
\Delta W_{0 k}=\alpha \delta_{k}
$$

Langkah 7: Hitung faktor $\delta$ unit tersembunyi berdasarkan kesalahan di setiap unit tersembunyi $\left(Z_{j}, j=1,2, \ldots, p\right)$

$$
\delta_{-} n e t_{j}=\sum_{k}^{m} \delta_{k} W_{j k}
$$

Faktor $\delta$ unit tersembunyi:

$$
\delta_{j}=\delta_{-} n e t_{j} f^{\prime}\left(Z_{-} n e t_{j}\right)
$$

Kemudian hitung koreksi bobot (yang nantinya akan digunakan untuk memperbaiki nilai $V_{i j}$ )

$$
\Delta V_{i j}=\alpha \delta_{j} x_{i}
$$

Kemudian hitung juga koreksi bias (yang nantinya akan digunakan untuk memperbaiki nilai $V_{0 j}$ )

$$
\Delta V_{0 j}=\alpha \delta_{j}
$$

Fase III: Perubahan Bobot

Langkah 8: Tiap-tiap unit output $\left(Y_{k}, k=1,2, \ldots, m\right)$ memperbaiki bobotnya $(j=0,1,2, \ldots, p)$

$$
W_{j k}(\text { baru })=W_{j k}(\operatorname{lama})+\Delta W_{j k}
$$

Tiap-tiap unit tersembunyi $\left(Z_{j}, j=1,2, \ldots, p\right)$ memperbaiki bobotnya $(j=0,1,2, \ldots, n)$

$$
V_{i j}(\text { baru })=V_{i j}(\text { lama })+\Delta V_{i j}
$$

Langkah 9: Kondisi pelatihan berhenti

Ketiga fase tersebut diulang terus menerus hingga kondisi penghentian dipenuhi. Umumnya kondisi penghentian yang sering dipakai adalah jumlah iterasi atau kesalahan. Iterasi akan dihentikan jika jumlah iterasi yang dilakukan sudah melebihi jumlah maksimum iterasi yang ditetapkan, atau jika kesalahan yang terjadi sudah lebih kecil dari batas toleransi yang diizinkan [15].

\subsection{Proses Penelitian}

Pada tahap proses penelitian dilakukan beberapa tahap secara sistematis, dimulai dari tahap studi literatur hingga tahap penarikan kesimpulan dari sistem yang telah dibuat dan diuji. Tahapan proses penelitian ini dapat dilihat pada diagram alir Gambar 3.

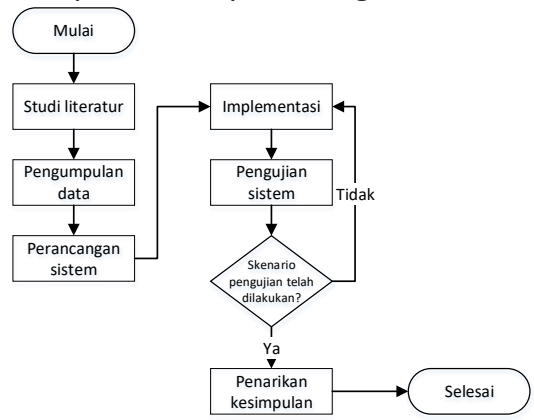

Gambar 3. Diagram alir tahapan proses penelitian 
a. Studi literatur

Studi literatur dilakukan dengan mempelajari buku - buku, jurnal penelitian serta sumber lain yang berkaitan dengan permasalahan yang diangkat. Adapun materi yang dipelajari dalam studi literatur berkaitan dengan Bahasa Arab, huruf hijaiah, kecerdasan buatan, pengolahan citra digital, neural network, metode gray level co-occurrence matrices dan metode backpropagation.

b. Pengumpulan data

Pengumpulan data dilakukan untuk memperoleh data yang akan digunakan dalam penelitian. Data yang berhasil dikumpulkan sebanyak 1500 citra huruf hijaiah dari 50 orang responden.

c. Perancangan sistem

Pada tahapan perancangan sistem ini terdiri dari perancangan arsitektur sistem dan perancangan desain sistem. Sistem dirancang agar dapat melakukan klasifikasi citra huruf hijaiah menggunakan metode GLCM dan backpropagation.

d. Implementasi

Pada tahapan implementasi akan dilakukan pembuatan program sistem berdasarkan perancangan yang telah dibuat pada tahap sebelumnya.

e. Pengujian Sistem

Pengujian sistem dilakukan untuk mengetahui kelayakan sistem berdasarkan tingkat akurasi. Jika seluruh skenario pengujian telah dilakukan, maka dapat dilanjutkan ke tahap selanjutnya.

f. Penarikan Kesimpulan

Penarikan kesimpulan didapatkan berdasarkan hasil pengujian dari sistem dan apakah sistem sudah mampu menjawab kebutuhan sistem berdasarkan dari tujuan penelitian.

\subsection{Pengujian Sistem}

Pengujian dilakukan menggunakan citra yang ada pada data uji. Hasil pengujian ini nantinya akan didapatkan tingkat akurasi dan presisi dari model yang dihasilkan ketika pelatihan backpropagation. Pada penelitian ini akan dilakukan pengujian kepada nilai ekstraksi fitur GLCM, pengaruh normalisasi terhadap nilai GLCM dan pengaruh cropping terhadap citra. Normalisasi mengubah nilai fitur ke dalam rentang 0 hingga 1, sehingga kinerja machine learning akan lebih optimal karena melakukan perhitungan dengan skala data yang cukup kecil. Proses cropping pada citra masukkan dilakukan agar mendapatkan ukuran tulisan yang sama untuk setiap citra masukkan. Setelah mendapatkan model pengujian terbaik, maka dilakukan pengujian untuk mengetahui pengaruh hidden layer. Terdapat beberapa skenario yang dirancang agar mendapatkan hasil akurasi dan presisi terbaik antara lain:

a. Pelatihan backpropagation menggunakan 20 node input layer, 30 output layer dan 3 hidden layer yaitu $(50,50,50,50),(100,100,100,100)$, $(150,150,150,150)$ dan $(150,50,100)$.

b. Pelatihan backpropagation menggunakan 20 node input layer, 30 output layer dan 2 hidden layer yaitu $(50,50),(100,100),(150,150)$ dan $(150,50)$.

c. Pelatihan backpropagation menggunakan 20 node input layer, 30 output layer dan 1 hidden layer (50, 100 dan 150).

\subsubsection{Confusion Matrix}

Confusion matrix berfungsi untuk melakukan analisis apakah classifier dapat mengenali tuple dari kelas berbeda. Nilai dari True-Positive dan TrueNegative memberikan informasi ketika classifier dalam melakukan klasifikasi bernilai benar, sedangkan FlasePositve dan False-Negative memberikan informasi ketika classifier salah dalam melakukan klasifikasi data [16].

\begin{tabular}{|c|c|c|c|}
\cline { 3 - 4 } \multicolumn{2}{|c|}{} & \multicolumn{2}{c|}{ Prediksi } \\
\cline { 3 - 4 } \multicolumn{2}{|c|}{ Aktual } & Benar & Salah \\
\hline & Benar & TP & FN \\
\cline { 2 - 4 } & Salah & FP & TN \\
\hline
\end{tabular}

Gambar 4. Confusion matrix

TP (True Positive) merupakan jumlah data dengan nilai sebenarnya positif dan nilai prediksi positif. FP (False Positive) merupakan jumlah data dengan nilai sebenarnya negatif dan nilai prediksi positif. FN (False Negative) merupakan jumlah data dengan nilai sebenarnya negatif dan nilai prediksi negatif. TN (True Negative) merupakan jumlah data dengan nilai sebenarnya positif dan nilai prediksi negatif. Perhitungan akurasi dan presisi model dapat dilakukan dengan menggunakan persamaan (21) dan (22) berikut ini:

$$
\begin{aligned}
& \text { Akurasi }=\frac{\sum_{T P_{i}+F N_{i}+F P_{i}+T N_{i}}}{l} \times 100 \% \\
& \text { Presisi }=\frac{\sum T P_{i}}{\sum T P_{i}+F P_{i}} \times 100 \%
\end{aligned}
$$




\section{4. hasil dan Pembahasan}

\subsection{Pengujian Terhadap Nilai Ekstraksi Fitur GLCM}

Pada penelitian ini dilakukan pengujian backpropagation terhadap nilai hasil ekstraksi fitur GLCM. Pengujian dilakukan dengan berbagai parameter antara lain learning rate, jumlah epoch dan pembagian data set. Berikut hasil pengujian terbaik disajikan pada Tabel I.

TABEL I. PenguJIAN TERHAdAP NILAI GLCM

\begin{tabular}{|l|l|l|l|l|}
\hline $\begin{array}{l}\text { Learning } \\
\text { rate }\end{array}$ & Epoch & $\begin{array}{l}\text { Variasi } \\
\text { data } \\
\text { set }\end{array}$ & $\begin{array}{l}\text { Akurasi } \\
(\%)\end{array}$ & $\begin{array}{l}\text { Presisi } \\
(\%)\end{array}$ \\
\hline $\mathbf{0 . 1}$ & $\mathbf{1 0 0 0}$ & $\mathbf{7 : 3}$ & $\mathbf{8 . 4 4 4 4}$ & $\mathbf{8 . 4 4 4 4}$ \\
\hline 0.3 & 2500 & $7: 3$ & 6 & 6 \\
\hline 0.5 & 1000 & $7: 3$ & 6 & 6 \\
\hline 0.1 & 2750 & $8: 2$ & 5.6667 & 5.6667 \\
\hline 0.3 & 2750 & $8: 2$ & 5.6667 & 5.6667 \\
\hline 0.5 & 1000 & $8: 2$ & 5.6667 & 5.6667 \\
\hline 0.1 & 2500 & $9: 1$ & 6.6667 & 6.6667 \\
\hline 0.3 & 2500 & $9: 1$ & 3.3333 & 3.3333 \\
\hline 0.5 & 1000 & $9: 1$ & 6 & 6 \\
\hline
\end{tabular}

Berdasarkan hasil pengujian backpropagation terhadap nilai hasil ekstraksi fitur GLCM pada Tabel I semakin banyak jumlah data uji yang digunakan maka rata - rata hasil akurasi testing meningkat, sedangkan pengaruh learning rate dan variasi data set cukup fluktuatif. Hasil terbaik terdapat pada pembagian jumlah data 7:3, learnig rate 0.1 dan jumlah epoch 1000 dengan akurasi pelatihan sebesar 5.8095\%, akurasi pengujian $8.4444 \%$ dan presisi sebesar $8.4444 \%$.

\subsection{Pengaruh Normalisasi Hasil Ekstraksi Fitur GLCM}

Pada penelitian ini dilakukan pengujian backpropagation terhadap nilai hasil ekstraksi fitur GLCM yang dilakukan normalisasi terhadap nilai tersebut ke dalam rentang nilai 0 hingga 1 . Pengujian dilakukan dengan berbagai parameter antara lain learning rate, jumlah epoch dan pembagian data set. Berikut hasil pengujian terbaik disajikan pada Tabel II.

TABEL II.PENGUJIAN TERHADAP DATA SETELAH DINORMALISASI

\begin{tabular}{|l|l|l|l|l|}
\hline $\begin{array}{l}\text { Learning } \\
\text { rate }\end{array}$ & Epoch & $\begin{array}{l}\text { Variasi } \\
\text { data } \\
\text { set }\end{array}$ & $\begin{array}{l}\text { Akurasi } \\
(\%)\end{array}$ & $\begin{array}{l}\text { Presisi } \\
(\%)\end{array}$ \\
\hline 0.1 & 2000 & $7: 3$ & 22.4444 & 22.4444 \\
\hline 0.3 & 2500 & $7: 3$ & 22.2222 & 22.2222 \\
\hline 0.5 & 2000 & $7: 3$ & 23.7778 & 23.7778 \\
\hline 0.1 & 2000 & $8: 2$ & 21.3333 & 21.3333 \\
\hline
\end{tabular}

\begin{tabular}{|l|l|l|l|l|}
\hline 0.3 & 2750 & $8: 2$ & 20 & 20 \\
\hline 0.5 & 2500 & $8: 2$ & 23.3333 & 23.3333 \\
\hline 0.1 & 2750 & $9: 1$ & 20 & 20 \\
\hline 0.3 & 1000 & $9: 1$ & 20 & 20 \\
\hline 0.5 & 2500 & $9: 1$ & 20.6667 & 20.6667 \\
\hline
\end{tabular}

Berdasarkan hasil pengujian backpropagation terhadap nilai hasil ekstraksi fitur GLCM yang dilakukan normalisasi ke dalam rentang nilai 0 hingga 1 pada Tabel II semakin banyak jumlah data uji yang digunakan maka rata - rata hasil akurasi testing meningkat, sedangkan pengaruh learning rate dan variasi data set cukup fluktuatif. Hasil terbaik terdapat pada pembagian jumlah data 7:3, learnig rate 0.5 dan jumlah epoch 2000 dengan akurasi pelatihan sebesar 49.5190\%, akurasi pengujian $23.7778 \%$ dan presisi sebesar 23.7778\%. Normalisasi terhadap hasil ekstraksi fitur GLCM berdampak cukup baik, akurasi pengujian secara rata - rata meningkat $15.0216 \%$ dibandingkan dengan akurasi pada proses sebelumnya.

\subsection{Pengaruh Penambahan Cropping Pada \\ Preprocessing}

Pada penelitian ini dilakukan pengujian backpropagation terhadap nilai hasil ekstraksi fitur GLCM yang dilakukan normalisasi terhadap nilai tersebut ke dalam rentang nilai 0 hingga 1 pada citra yang di - crop untuk mengurangi pengaruh latar putih pada citra masukkan. Pengujian dilakukan dengan berbagai parameter antara lain learning rate, jumlah epoch dan pembagian data set. Berikut hasil pengujian terbaik disajikan pada Tabel III.

TABEL III. PEnguJIAN TERHADAP PENGARUH CROPPPING SAAT PREPROCESSING

\begin{tabular}{|l|l|l|l|l|}
\hline $\begin{array}{l}\text { Learning } \\
\text { rate }\end{array}$ & Epoch & $\begin{array}{l}\text { Variasi } \\
\text { data } \\
\text { set }\end{array}$ & $\begin{array}{l}\text { Akurasi } \\
(\%)\end{array}$ & $\begin{array}{l}\text { Presisi } \\
\text { (\%) }\end{array}$ \\
\hline $\mathbf{0 . 1}$ & $\mathbf{2 5 0 0}$ & $\mathbf{7 : 3}$ & $\mathbf{4 1 . 1 1 1 1}$ & $\mathbf{4 1 . 1 1 1 1}$ \\
\hline 0.3 & 2500 & $7: 3$ & 40 & 40 \\
\hline 0.5 & 2500 & $7: 3$ & 38.6667 & 38.6667 \\
\hline 0.1 & 2750 & $8: 2$ & 32 & 32 \\
\hline 0.3 & 2750 & $8: 2$ & 35.6667 & 35.6667 \\
\hline 0.5 & 2750 & $8: 2$ & 33.3333 & 33.3333 \\
\hline 0.1 & 2750 & $9: 1$ & 24.6667 & 24.6667 \\
\hline 0.3 & 2000 & $9: 1$ & 20.6667 & 20.6667 \\
\hline 0.5 & 2500 & $9: 1$ & 20.6667 & 20.6667 \\
\hline
\end{tabular}

Berdasarkan hasil pengujian backpropagation terhadap nilai hasil ekstraksi fitur GLCM yang dilakukan normalisasi ke dalam rentang nilai 0 hingga 1 pada citra yang di - crop untuk mengurangi pengaruh latar putih pada citra masukkan, pada Tabel III semakin tinggi learning rate yang digunakan maka rata - rata akurasi 
testing menurun, sedangkan semakin banyak jumlah data uji yang digunakan maka rata - rata hasil akurasi testing meningkat, kemudian pengaruh variasi data set cukup fluktuatif. Hasil terbaik terdapat pada pembagian jumlah data 7:3, learnig rate 0.1 dan jumlah epoch 2500 dengan akurasi pelatihan sebesar $89.1429 \%$, akurasi pengujian $41.1111 \%$ dan presisi sebesar $41.1111 \%$, dengan demikian maka konfigurasi yang akan digunakan pada pengujian berikutnya adalah pembagian data set 7:3, learning rate 0.1 dan jumlah epoch 2500.

Proses cropping terhadap citra masukkan pada tahap preprocessing berdampak cukup baik, akurasi pengujian secara rata - rata meningkat $10.9167 \%$ dibandingkan dengan akurasi pada proses sebelumnya. Rata - rata akurasi pengujian dapat dilihat pada Gambar 5.

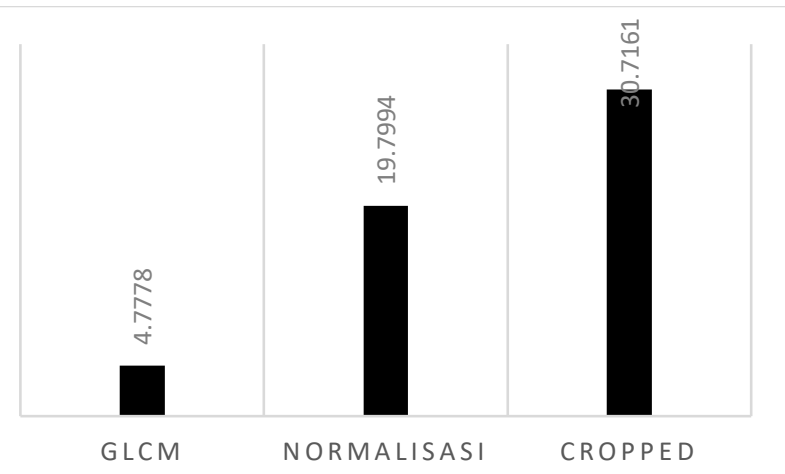

Gambar 5. Rata - rata akurasi pengujian backpropagation

\subsection{Pengaruh Variasi Jumlah Hidden Layer}

Pada penelitian ini dilakukan pengujian backpropagation terhadap pengaruh variasi hidden layer dengan konfigurasi sesuai hasil pengujian pada sub bagian 4.3. Berikut hasil pengujian terbaik disajikan pada Tabel IV.

TABEL IV. PengujIAN TeRhadap PENGaruh VARIASI HIDDEN LAYER

\begin{tabular}{|c|c|c|c|}
\hline $\begin{array}{c}\text { Jumlah } \\
\text { hidden } \\
\text { layer }\end{array}$ & Neuron & Akurasi (\%) & Presisi (\%) \\
\hline 3 & $150,50,100$ & 41.1111 & 41.1111 \\
\hline 2 & 50,50 & 41.5556 & 41.5556 \\
\hline $\mathbf{1}$ & $\mathbf{5 0}$ & $\mathbf{4 5 . 1 1 1 1}$ & $\mathbf{4 5 . 1 1 1 1}$ \\
\hline
\end{tabular}

Pengujian backpropagation terhadap pengaruh variasi hidden layer dengan konfigurasi parameter terbaik berdasarkan hasil pengujian sebelumnya, mendapatkan hasil terbaik terdapat pada konfigurasi jumlah hidden layer sebanyak 1 layer dan neuron sejumlah 50 dengan akurasi pelatihan sebesar $56.7619 \%$, akurasi pengujian $45.1111 \%$ dan presisi sebesar $45.1111 \%$. Pengurangan jumlah hidden layer menyebabkan akurasi pengujian meningkat.

Jumlah data set yang digunakan cukup sedikit untuk jumlah kelas yang banyak seperti pada penelitian ini menyebabkan tingkat akurasi tidak sesuai harapan. Hasil klasifikasi kurang maksimal juga dapat disebabkan fitur - fitur yang kurang relevan dan tidak dapat mewakili keadaan data yang sesungguhnya. Terdapat cukup banyak fitur yang memiliki nilai korelasi yang mendekati 0 , seperti terlihat pada Gambar 6.

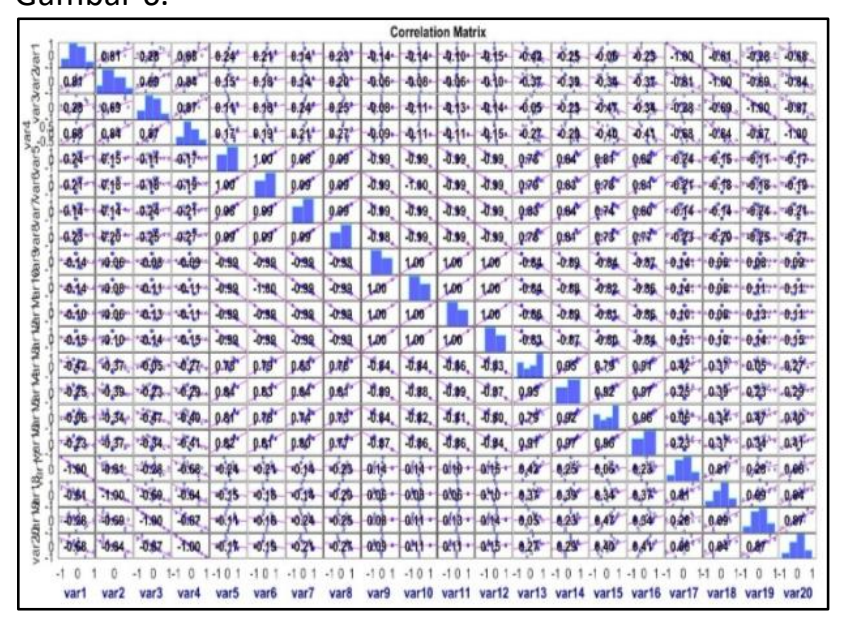

Gambar 6. Correlation matrix

\section{KESIMPULAN DAN SARAN}

\subsection{Kesimpulan}

Berdasarkan hasil penelitian dan analisis yang telah dilakukan, dapat diambil kesimpulan sebagai berikut:

a. Model arsitektur JST backpropagation terbaik untuk penelitian pengenalan huruf hijaiah ini yaitu menggunakan 1 hidden layer dengan jumlah node sebanyak 50, learning rate sebesar 0.1 , dengan epoch sebanyak 2500 kali perulangan dan pembagian data set 7:3.

b. Tingkat akurasi tertinggi dari model arsitektur pengujian terhadap pengaruh variasi hidden layer adalah $56.7619 \%$ untuk pengenalan data latih, 45.1111\% untuk pengenalan data uji dan presisi sebesar $45.1111 \%$.

c. Luas latar belakang berwarna putih pada citra masukkan sangat berpengaruh terhadap tingkat akurasi pada klasifikasi citra huruf 
hijaiah menggunakan metode GLCM dan backpropagation. Semakin besar latar belakang dari sebuah citra masukkan, maka objek akan semakin sulit dikenali. Semakin kecil latar belakang dari sebuah citra masukkan, maka objek akan semakin mudah untuk dikenali.

d. Normalisasi data hasil ekstraksi fitur dan proses cropping dapat meningkatkan akurasi pengujian dari $8.4444 \%$ hingga $45.1111 \%$.

e. Perlakuan terhadap data yang tepat seperti cropping dan resize memberikan dampak yang signifikan terhadap peningkatan akurasi pengenalan citra huruf hijaiah ini.

f. Metode GLCM dan backpropagation kurang maksimal dalam pengenalan citra huruf hijaiah dengan jumlah data set yang sangat terbatas yaitu hanya 1500 data, dibuktikan dengan terjadinya penurunan tingkat akurasi saat jumlah data uji dikurangi.

\subsection{Saran}

Berdasarkan hasil penelitian, analisis dan kesimpulan di atas, penulis dapat memberikan beberapa masukkan atau saran untuk penelitian lebih lanjut antara lain:

a. Memilih fitur yang paling relevan dan dapat mewakili keadaan data yang sesungguhnya sehingga dapat dilakukan klasifikasi dengan baik.

b. Perlakuan terhadap data pada saat preprocessing harus diperhatikan agar bisa melakukan klasifikasi dengan baik dan mendapatkan akurasi yang tinggi.

c. Menambah jumlah data set dalam jumlah yang besar, agar mendapatkan hasil tingkat akurasi yang lebih maksimal untuk pengenalan citra huruf hijaiah menggunakan metode klasifikasi backpropagation.

d. Pengumpulan data harus dipersiapkan secara maksimal dan dilakukan mengikuti konfigurasi yang telah ditentukan agar mendapatkan data sesuai kondisi yang diinginkan.

\section{DAFTAR PUSTAKA}

[1] "What are the official languages of the United Nations? - Ask DAG!" http://ask.un.org/faq/14463 (accessed Oct. 24,
2019).

[2] A. Haralick, Robert M., Shanmugam. K and I. Dinstein, "Textural Features for Image Classification," IEEE Trans. Syst. Man Cybern., vol. SMC-3, no. 6, pp. 610-621, 1973.

[3] K. B. Putri and N. L. Marpaung, "Identifikasi Huruf Hijaiyah Berbasis GLCM Menggunakan Jaringan Syaraf Tiruan BackPropagation," Jom FTEKNIK, vol. 6, no. 1, pp. 2-6, 2019.

[4] I. A. Kanta, "Pengenalan Pola Huruf Hijaiyah Tulisan Tangan Menggunakan Logika Fuzzy Dengan Jaringan Syaraf Tiruan Backpropagation," Jurusan Teknik Informatika Fakultas Komunikasi dan Informatika Universitas Muhammadiyah Surakarta. 2013.

[5] A. Sanjaya and D. W. Widodo, "Identifikasi Tulisan Tangan Huruf Hijaiyah," J. IIm. NERO, vol. 4, no. 1, pp. 23-29, 2018.

[6] Vidia, "Pengenalan Tulisan Tangan Bahasa Arab Menggunakan Metode Probabilistic Neural Network," J. Ilmu Komput. dan Desain Komun. Vis., vol. 4, no. 1, pp. 28-35, 2019.

[7] Sutarno and P. A. Garini, "Pengenalan Angka Arab Timur Tulisan Tangan Menggunakan Zone Centroid Zone ( ZCZ ) dan Backpropagation," 2017.

[8] A. S. Kholimi and F. Nazihullah, "Identifikasi Tulisan Arab Dengan Menggunakan GLCM Dan RNN," 2018.

[9] N. R. Angraheni, R. Efendi, and E. P. Purwandari, "Pengenalan Tullisan Tangan Huruf Hijaiyah Sambung Menggunakan Algoritma Tamplate Matching Correlation," J. Rekursif, vol. 5, no. 1, 2017.

[10] E. Y. Subairi, Rahmadwati, "Implementasi Metode k-Nearest Neighbor pada Pengenalan Pola Tekstur Citra Saliva untuk Deteksi Ovulasi," J. EECCIS, vol. 12, no. 1, pp. 9-14, 2018.

[11] E. Budianita, Jasril, and L. Handayani, "Implementasi Pengolahan Citra dan Klasifikasi K-Nearest NeighbourUntuk Membangun Aplikasi Pembeda Daging Sapi dan Babi," J. Sains, Teknol. dan Ind., vol. 12, no. 2, pp. 242-247, 2015.

[12] F. S. Ni'mah, T. Sutojo, and D. R. I. M. Setiadi, "Identifikasi Tumbuhan Obat Herbal Berdasarkan Citra Daun Menggunakan Algoritma Gray Level Co-occurence Matrix dan K-Nearest Neighbor," J. Teknol. dan Sist. Komput., vol. 6, no. 2, pp. 5156, 2018, doi: 10.14710/jtsiskom.6.2.2018.51-56.

[13] Y. K. Ganis, I. Santoso, and R. R. Isnanto, "Klasifikasi Citra Dengan Matriks Ko-okurensi Aras Keabuan ( Gray Level Co-occurrence Matrix -GLCM ) Pada Lima Kelas Biji-Bijian," Undergrad. thesis, Jur. Tek. Elektro Fak. Tek. Univesitas Diponegoro, pp. 1-7, 2011. 
[14] L. Fausett, Fundamentals of Neural Networks: Architectures, Algorithms, and Applications. Melbourne, 1994.

[15] A. Jumarwanto, R. Hartanto, and D. Prastiyanto, “Aplikasi Jaringan Syaraf Tiruan Backpropagation Untuk Memprediksi Penyakit THT di Rumah Sakit Mardi Rahayu Kudus," J. Tek. Elektro, vol. 1, no. 1, pp. 11-21, 2009.

[16] M. F. Fibrianda and A. Bhawiyuga, "Analisis
Perbandingan Akurasi Deteksi Serangan Pada Jaringan Komputer Dengan Metode Naïve Bayes Dan Support Vector Machine ( SVM )," J. Pengemb. Teknol. Inf. dan IImu Komput., vol. 2, no. 9, pp. 3112-3123, 2018. 